\title{
Implementation of BIM Modelling and Simulation Tools in Reducing Annual Energy Consumption of Multifamily Dwellings
}

\author{
Subbarao Yarramsetty ${ }^{{ }^{*}}$, Siva Kumar $M V N^{l}$, and Anand Raj $P^{l}$ \\ ${ }^{1}$ Department of Civil Engineering, NIT Warangal, Telangana State-506 004, India.
}

\begin{abstract}
In current research, building modelling and energy simulation tools were used to analyse and estimate the energy use of dwellings in order to reduce the annual energy use in multifamily dwellings. A three-story residential building located in Kabul city was modelled in Revit and all required parameters for running energy simulation were set. A Total of 126 experiments were conducted to estimate annual energy loads of the building. Different combinations from various components such as walls, roofs, floors, doors, and windows were created and simulated. Ultimately, the most energy efficient option in the context of Afghan dwellings was figured out. The building components consist of different locally available construction materials currently used in buildings in Afghanistan. Furthermore, the best energy efficient option was simulated by varying, building orientation in 15-degree increments and glazing area from $10 \%$ to $60 \%$ to find the most energy efficient combination. It was found that combination No. 48 was best option from energy conservation point of view and 120-degree rotational angle from north to east, of the existing building was the most energy-efficient option. Also, it was observed that $60 \%$ glazing area model consumed $24549 \mathrm{kWh}$ more electricity compared to the one with $10 \%$ glazing area.
\end{abstract}

\section{Introduction}

The energy efficiency of buildings is a much debated and research area in Architecture, Engineering, and Construction (AEC) sector nowadays. It plays an important role in impacting environment, determining the life-cycle cost of projects, helping carbon reduction and global warming and ensuring sustainability issues. Minimizing energy demand of buildings by increasing building energy efficiency is the need of the hour due to the growth of population and high demand for fuel and electricity. Thus, clean energy solutions and energy conservation measures are absolutely essential for the future.

$40 \%$ of total primary energy production of the world is consumed by buildings and they are responsible for producing $30 \%$ carbon dioxide emissions [1]. Applying of insulation materials to building envelopes significantly reduces energy demand, but most of the builders in Afghanistan don't use insulation materials in buildings, as energy performance of residential areas is comparatively low. The building industry in Afghanistan consumes about $71 \%$ of total domestic electricity [2].

Energy consumption analysis of dwelling is the most important factor in AEC industry because of its direct impact on lifecycle cost of buildings and environmental issues. Energy simulation needs to be conducted in early design phases of the project in order to take appropriate decision on design alternatives. Traditional energy analysis techniques are not adequate to deliver accurate simulation results due to their drawbacks and shortages. Utilizing proper software tools and systems for the anticipation of energy demand in buildings is very essential nowadays. Therefore, building information modeling (BIM) is used as a dominant contemporary program for this purpose.

Climate variation in Afghanistan is complicated. It depends on different zones and different seasons. Some regions of the country are very hot and some regions are very cold. Generally, Afghanistan is known as a dry continental climate country with cold and relatively rainy weather in winter and hot and sunny weather in summer. Even though numerous researches have been conducted on the building energy behavior on energy consumption based on climate variation worldwide, not enough literature has been published on this topic in the context of Afghanistan.

Energy consumption will increase in the future all over the world because of increase in population, enhancement of social and economic conditions, and high demand for services which need energy [3]. According to International Energy Agency (IEA), the global total primary energy consumption and $\mathrm{CO}_{2}$ emissions grew by $49 \%$ and $43 \%$ respectively, with an average annual rise of $2 \%$ and $1.8 \%$ from 1984 to 2004 . While in 2012 , energy use and $\mathrm{CO}_{2}$ discharges increased by $85 \%$ and $75 \%$ respectively. Total world energy use is anticipated to increase by almost $32 \%$ and $\mathrm{CO}_{2}$ emission is projected to grow by approximately $16 \%$ until 2035 [4,5]. Table 1 represents global energy demand projection of different organizations including British multinational oil \& gas Company (BP), European Commission (EC), Energy Information Administration (EIA), International Atomic Energy Agency (IAEA), International Energy Agency, International Institute for Applied Systems Analysis (IIASA), Shell International, World Energy Council

*Corresponding author: sraoystp@student.nitw.ac.in 
(WEC) and Tellus Institute for the future. According to IIASA's perception, global energy consumption is anticipated to increase up to 1740 EJ (exajoules) in 2100 [6].

Table 1. World Energy Anticipation (from 2020 To 2100), in $\mathrm{EJ}(\mathrm{EJ}=1018 \mathrm{~J})$, Adopted from [6]

\begin{tabular}{|c|l|l|l|c|c|}
\hline Institutes & Year & $\mathbf{2 0 2 0}$ & $\mathbf{2 0 3 0}$ & $\mathbf{2 0 5 0}$ & $\mathbf{2 1 0 0}$ \\
\hline BP & $(2011)$ & $565-635$ & $600-760$ & NA & NA \\
\hline EC & $(2006)$ & $570-610$ & $650-705$ & 935 & NA \\
\hline EIA & $(2010)$ & $600-645$ & $675-780$ & NA & NA \\
\hline IAEA & $(2009)$ & $585-650$ & $670-815$ & NA & NA \\
\hline IEA & $(2010)$ & NA & $605-705$ & NA & NA \\
\hline & & & & $800-$ & $985-$ \\
IIASA & $(2007)$ & $555-630$ & NA & 1175 & 1740 \\
\hline Shell & & & & $770-$ & \\
International & $(2008)$ & $630-650$ & $690-735$ & 880 & NA \\
\hline & & & & $845-$ & \\
WEC & $(2008)$ & $615-675$ & $700-845$ & 1150 & NA \\
\hline Tellus & & & & $425-$ & $243-$ \\
Institute & $(2010)$ & $504-644$ & $489-793$ & 1003 & 1200 \\
\hline
\end{tabular}

\subsection{BIM \& BEP}

For better assessment of energy demand in the buildings, the following factors must be taken into consideration which includes equipment use, geographic location, number of occupancies, construction materials, size and space of buildings, etc. Much of the information must be provided early in the design phases by the designer [7]. Most of the countries believe that construction sector is the most complicated and risky industry [8]. Today BIM is used in USA, Europe, and some other countries for energy simulation and validation purposes [9]. Compared to BIM, other energy simulation tools are very expensive, time-consuming, difficult to run and unable to evaluate all characteristics of energy in building simulation trend [10]. BIM allows designers to select the most energy effective construction materials for the buildings by investigating various alternatives and systems early in the conceptual phase of the project. By utilizing BIM, users don't need to reinter geometry and other data required for energy simulation which leads comprehensive saving of time [11].

Building energy performance (BEP) is a vast computer-based building analysis software which is used for different purposes, such as assessment of loads, complete energy analysis of buildings, inside air quality and its flow analysis, lighting system design, code compliance, retrofit, analysis of renewable energy and economic assessment [12]. BEP tools are commonly divided into two parts: design tools and simulation tools. Design tools are used to study the worst-case scenarios for determining optimum size of HVAC systems. Energy analysis tools take dynamic calculations into consideration for whole year studies [13]. Despite numerous building analysis software tools, the real implementation of the tools is mostly confined to computation of energy load for complete designing of heat, ventilation as well as air-condition (HVAC) systems[14]. Energy Plus, eQuest, and Ecotect are examples of Building Performance Simulation (BPS) software tools. Engineers, scholars, and architects in general use BEP tools for a detailed evaluation of energy consumption such as heating and cooling loads as well as other required parameters of both new and existing buildings by preparing energy models to increase the thermal efficiency of the buildings [15].

\subsection{Buildings in Afghanistan:}

The selection of construction materials and techniques depends on the local situations and conditions such as affordability, climate changes, material availability, culture, and social living schema, etc.

People in Afghanistan build different types of houses. the main types of construction material used in buildings are Sun-dried (Adobe) brick or mud walls with wooden roofs and floors, fired brick walls $(350 \mathrm{~mm})$ with barrel-arch (Taqe-Zarbi) roofs and floors, fired or adobe brick with dome roofs. Contemporary buildings generally use fired brick $(220 \mathrm{~mm})$ and concrete masonry unit block (200mm) walls with Reinforced Cement Concrete (RCC) roofs and floors. The majority of existing houses are constructed with adobe brick walls and wooden slabs as well as mud walls and dome roofs all over the country. The primary construction material locally available is Mud, which contributed to $95 \%$ of construction material in Afghanistan. Contemporary materials are used only in urban areas[16].

A typical family in Afghanistan is relatively big and varies between 8-14 persons. Traditionally married and unmarried brothers used to live with parents together in the same building. For this reason, people prefer building multifamily houses. The area of the buildings starts from $100 \mathrm{~m}^{2}$ onwards. In urban areas, people extend their houses vertically while in rural areas extension of buildings is done horizontally.

Today energy is one of the most important factors which helps countries to enhance their economy and bring numerous facilities and services in societies. Afghanistan is a rich country from the point of energy resources. According to the Ministry of Energy and Water 2016, Afghanistan has the capacity of generating $2300 \mathrm{MW}$ of electricity from hydropower plant, $158500 \mathrm{MW}$ from wind power, 4000MW from biomass, and 3500MW from solar power as a clean and environmentally friendly energy source. But due to political and security issues, no significant investment has been made in this sector yet. Thus, the major energy needs of the country come from abroad. On the consumption side, houses in Afghanistan contributed to consumption of $71 \%$ of overall electricity use in the country, industrial buildings $11 \%$, public buildings $-11 \%$ and commercial buildings $-7 \%$ [2]. Nowadays most of the houses consume wood, coal, charcoal, gas, diesel, kerosene, and even animal dung, which leads to various environmental problems. Houses 
in Afghanistan, need the highest amount of energy in winter season compared to summer [2,17].

\section{Methodology}

The main purpose of this research was to minimize annual energy consumptions of multifamily residential dwellings without compromising comfort, health or productivity levels of the buildings, utilizing BIM-based modelling and Energy simulation software tools. The research objectives are presented below:

$\checkmark$ Gathering information regarding available materials used in buildings in Afghanistan

$\checkmark \quad$ Creating 2D Plans of the benchmark buildings based on site measurement data in AutoCAD

$\checkmark \quad$ Creating a 3D BIM model by importing 2D plans of the model to Autodesk Revit Architecture

$\checkmark \quad$ Utilizing Revit energy plug-in and GBS for energy simulation.

$\checkmark$ Evaluating energy analysis results of different combinations of building's components to achieve the best combination from energy use point of view.

$\checkmark$ Investigate energy performance by varying the orientation of the building.

$\checkmark \quad$ Check impact of increasing glazing area on energy consumption of the building.

\section{Case Study Building}

The case study building is an existing three-story residential typical dwelling, located in Kabul city as shown in Figure 1. For research purpose, we are assuming that the building is still in design phase. The building plan area is $125 \mathrm{~m}^{2}$.

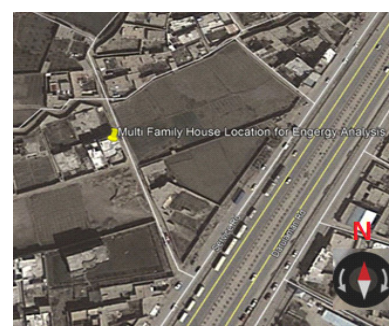

(a)

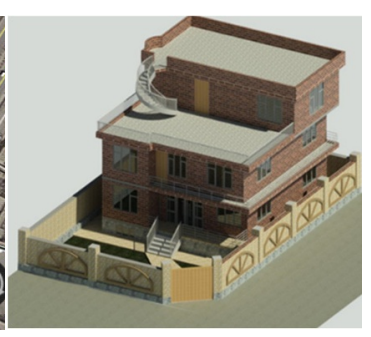

(b)
Fig. 1. (a) Location - satellite image, (b) 3D Front view of the Building.

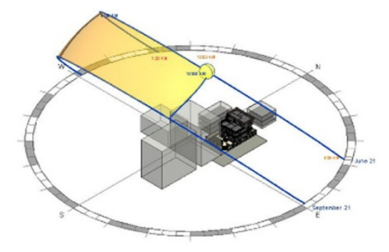

(a)

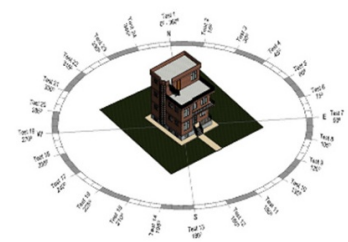

(b)
Fig. 2. (a) existing surrounding buildings, (b) Test scenarios for orientation analysis.
Basement walls of the building consist of $600 \mathrm{~mm}$ thick stone masonry, where conventional stones are used in basement walls and foundations in construction of buildings in Afghanistan. This wall remains unchanged with all combinations across the energy performance assessment process. The nearest weather station for the building is station No. 699799 which was assigned to software for energy simulation. The building has a box shape and its roof is flat. South-East façade of the building has its entrance on the Ground floor. The North-West and South-West facades of the building have small windows while North-East and South-East façades have larger windows.

\section{BIM modelling and Analysis}

BIM modelling is the most essential step involved in thermal analysis process. Modelling for energy performance analysis is slightly different than that of architecture designs. Any likely mistakes in this process hugely impact the result of the analysis. For this purpose, sufficient and correct information must be set into the model. Energy analysis is one of the important features of the rivet which performs whole building energy analysis. There are two ways in Revit for energy analysis simulation: 1) Using conceptual masses where actual physical parts of the building components are not required to be included in the model. 2) Using building elements when actual model with all materials and elements including their properties need to be included in the model. In the present study, building element method was used as the base to perform simulation analysis. Fig. 3 . Shows the model generated using Revit and the process involved in extracting energy analysis. As soon as BIM model was created, a few modifications were made to obtain accurate result from the energy analysis process.

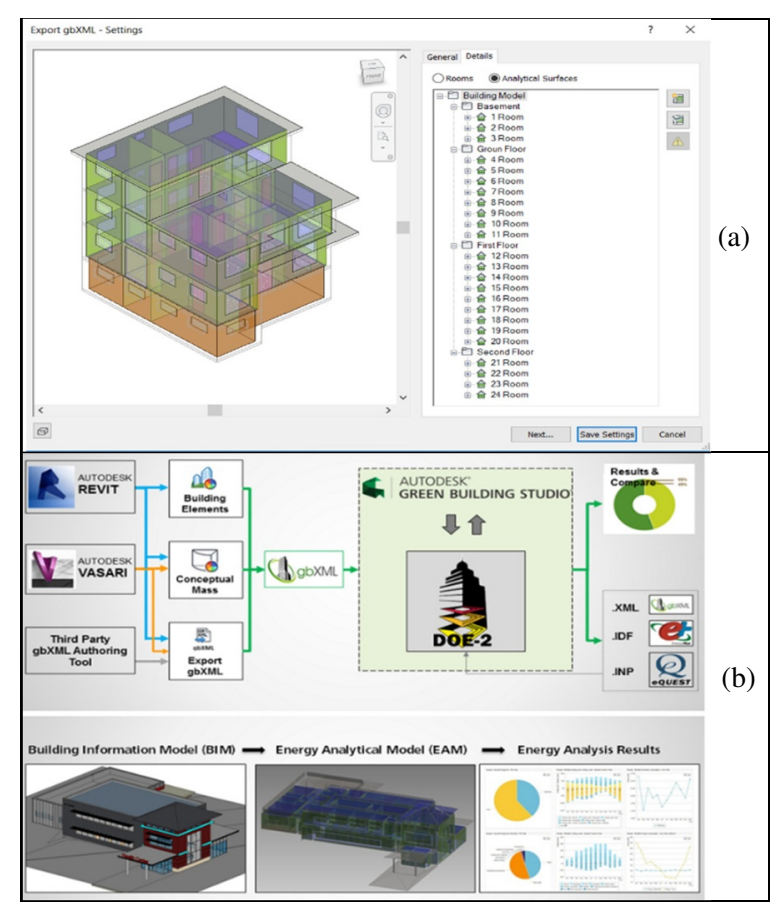


Fig. 3. (a) gbXML file of the model in Revit, (b) Energy Analysis Work Flow in Autodesk tools

\subsection{Building envelope Variation Impacts}

In the current study, gbXML files of all combinations were imported from Revit to GBS cloud. Table 2 shows the default simulation parameters used in GBS studio. Locally available materials which are typically used in the envelop of residential buildings in Afghanistan were used. A total of 127 models (96 building envelope +24 orientation analysis +7 analysis for glazing impacts) were analyzed for energy estimates. For this purpose, 6 types of walls, 4 types of floors, and 4 types of roofs were taken into consideration. 96 ( $\mathrm{C} 1$ to $\mathrm{C} 96)$ different combinations of Afghan local construction materials for the envelope of the residential buildings were studied. As the result of energy analysis experiments, it was found that a combination-C48 of wall type (W3)- Adobe brick wall, roof type (R4)- Mud Roof with timber as core structure and Floor type (F4)-Mud floor with timber as structure, was the best option that consumed least amount of energy leading to reduction in annual electricity demand. The work carried in identifying the best combination of building material is not presented here, and only its outcome is used for orientation and glazing analysis. The minimum energy consumption combination is tabulated in Table 3.

Table 2. Default values for multifamily building in GBS

\begin{tabular}{|c|c|c|c|c|c|}
\hline 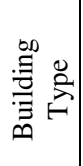 & 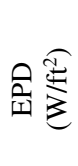 & $a \frac{\overparen{E}}{\xi}$ & 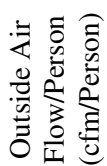 & 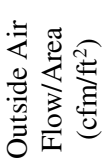 & 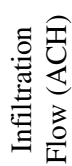 \\
\hline 至 & 1 & 0.7 & N/A & 0.06 & 0.25 \\
\hline
\end{tabular}

Table 3. Minimum energy demand - combination C48

\begin{tabular}{|c|c|c|c|c|}
\hline $\begin{array}{c}\text { Wall } \\
\text { Type }\end{array}$ & $\begin{array}{c}\text { Roof } \\
\text { Type }\end{array}$ & $\begin{array}{c}\text { Floor } \\
\text { Type }\end{array}$ & $\begin{array}{c}\text { Electricity } \\
\text { Demand } \\
\text { (KWh) }\end{array}$ & $\begin{array}{c}\text { Electricity } \\
\text { Annual } \\
\text { Cost (AF) }\end{array}$ \\
\hline W3 & R4 & F4 & $29,496.00$ & $2,13,846.00$ \\
\hline
\end{tabular}

\subsection{Orientation Variation Impacts}

The building was rotated clockwise from the North side of the building with $15^{\circ}$ rotational angle interval. A total of 24 tests were performed; test details are marked in Fig. 2 (b) along with actual orientation. The result shows that test 7 with $90^{\circ}$ rotation angle was the most efficient option from an energy conservation point of view. It indicates $8.22 \%$ energy efficiency improvement compared to actual oriented option (test 23 with $330^{\circ}$ rotational angle) which is the worst case from the energy conservation point of view. Fig. 4 show complete results of the tests for all rotated angles.

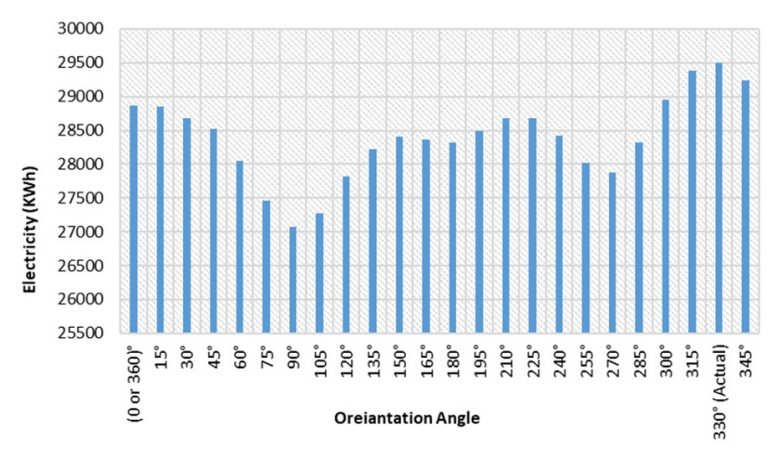

Fig. 4. Electricity demand of all orientation change increment

\subsection{Glazing area variation results}

Glazing area of the building envelope of the most energy efficient case (C48) was increased from $10 \%$ to $60 \%$ with $10 \%$ WWR increment intervals. For this purpose, the percentage of glazing area of models for $10 \%$ to $60 \%$ as well as the actual model were calculated in Microsoft Excel and new windows with new dimensions were assigned to the models accordingly. Then energy simulation was conducted for all 6 new models. Finally, electricity demand results in all models were compared. Detailed result of Energy demand is shown in Table 4 and Fig. 5.

Table 4. Electricity demand for different glazing area

\begin{tabular}{|c|c|c|c|}
\hline Com. No. & $\begin{array}{c}\text { Windows } \\
\text { to Wall } \\
\text { Ratio } \\
\text { (WWR) }\end{array}$ & $\begin{array}{c}\text { Electricity } \\
\text { Demand } \\
\text { (KWh) }\end{array}$ & $\begin{array}{c}\text { Electricity } \\
\text { Cost } \\
\text { (AF) }\end{array}$ \\
\hline C48_1 & $10 \%$ & 24356 & 176584 \\
\hline C48_2 & $20 \%$ & 28442 & 206204 \\
\hline C48_3 (Actual) & $20.3 \%$ & 29496 & 213846 \\
\hline C48_4 & $30 \%$ & 33831 & 245276 \\
\hline C48_5 & $40 \%$ & 39728 & 288025 \\
\hline C48_6 & $50 \%$ & 44126 & 319911 \\
\hline C48_7 & $60 \%$ & 48885 & 354417 \\
\hline
\end{tabular}

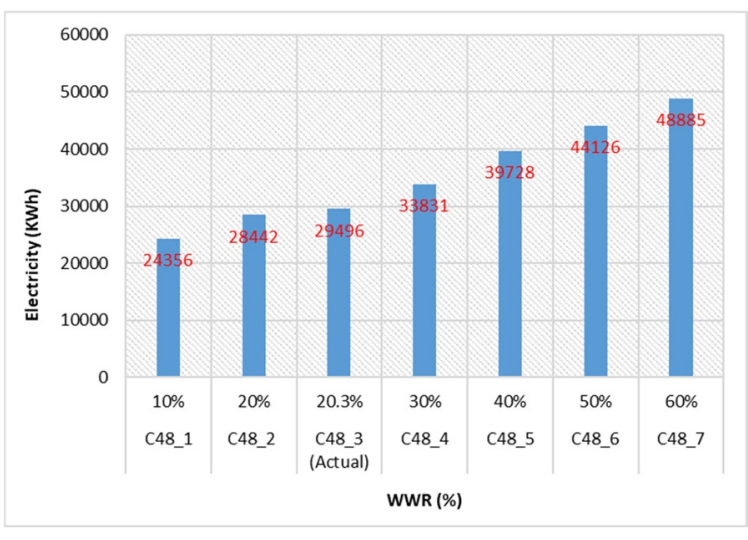

Fig. 5. Variation of Electricity demand for variation in glazing area 


\section{Conclusion}

Due to technological developments, numerous software tools have been developed in energy assessment in the construction industry. Building energy evaluation allows the users to make proper decisions at different stages of design to enhance sustainability by applying specific solutions.

The aim of this research was to identify proper measures for improving living standards by reducing annual energy consumption in Afghan multifamily dwellings with the implementation of BIM technology. The main reason for using BIM based software tools in this project was the potential they have to achieve the project goals quickly and accurately without imposing any charges for software acquisition. From the other side, learning BIM software tools for 3D modelling and energy analysis is very easy and many online resources are available to learn the software quickly.

Revit Architecture and Green Building Studio two BIM based software tools were used to create and simulate a three-story building located in Kabul city. AutoCAD 2D plans were used as a baseline to build the 3D model quickly, and Microsoft Excel was used for cost estimation and creating various tables and graphs in the research project.

The main objective of the research was to investigate local construction material behaviour on building energy consumption. For this purpose, different local construction materials which are conventionally used in buildings were assigned to main components of the 3D model in Revit. In all 7 types of walls, 4 types of roofs, and 4 types of floors were created from various local materials, and all the aforementioned building elements were combined to gather and 96 models were built. gbXML format of all 96 models was imported to GBS cloud for energy simulation. Finally, it was observed that combination No. 48 which was made of adobe brick walls and mud roofs and floors was the best one from energy conservation point of view as it consumes 29496 $\mathrm{KWh}$ electricity annually which is the minimum electricity consumption among all combinations.

Furthermore, building orientation variation and glazing area enlargement impact were investigated to find out the best rotation angle and favourable percentage of WWR from energy conservation point of view. For this purpose, the most energy efficient combination model was rotated clockwise with $15^{\circ}$ increment angle and 24 new models were built for orientation changing tests and 6 new models were prepared for $10 \%$ to $60 \%$ WWR experiments. It was observed that $120^{\circ}$ rotation angle for existing building orientation state was the best choice. By increasing WWR percentages, electricity demand also increased accordingly. So, to build energy efficient buildings, smaller WWR is recommended.

\section{References}

1. A. Costa, M. M. Keane, J. I. Torrens, and E. Corry, Appl. Energy 101, 310 (2013).

2. O. T. Mohmmad, Energy Efficiency Guidbook for
Buildings. (2017).

3. N. Nebojia and J. M. Jefferson, Global Energy

Perspectives to 2050 and Beyond (1995).

4. X. Cao, X. Dai, and J. Liu, Energy Build. 128, 198 (2016).

5. L. Pérez-Lombard, J. Ortiz, and C. Pout, Energy

Build. 40, 394 (2008).

6. P. Moriarty and D. Honnery, Renew. Sustain. Energy Rev. 16, 244 (2012).

7. H. Kim and K. Anderson, J. Comput. Civ. Eng. 27, 203 (2013).

8. C. M. Clevenger, M. E. Ozbek, H. Mahmoud, and B. Fanning, Impacts and Benefits of Implementing Building Information Modeling on Bridge Infrastructure Projects (2014).

9. T. Laine and A. Karola, in Clima 2007 WellBeing Indoors (2007).

10. A. Venkataraman and K. M. Ramesh, in Proc. Int. Conf. Adv. Civ. Eng. AETACE (2013).

11. F. Jalaei and A. Jrade, J. Inf. Technol. Constr. 19, 494 (2014).

12. V. Ugursal, Buildings 4, 762 (2014).

13. M. Senave and S. Boeykens, in Build. Inf. Model.

Des. Constr. Oper. (2015).

14. C. J. Hopfe, Uncertainty and Sensitivity Analysis in Building Performance Simulation for Decision Support and Design Optimization (2009).

15. Y. Ham and M. Golparvar-Fard, Energy Build. 63, (2013).

16. A. S. Arya, Guidelines for Earthquake Resistant

Design, Construction, and Retrofitting of Buildings in Afghanistan (2003).

17. A. M. Ershad, R. J. Brecha, and K. Hallinan, Renew. Energy 85, (2016). 